\title{
ET ÜRÜNLERİNDE TUZUN FONKSIYYONLARI, TUZ AZALTILMASI AMACIYLA KULLANILAN İKAME KATKILAR ve ETKİLERİ
}

\author{
Gülen Yıldız Turp*, Ayşegül Atalı \\ Ege Üniversitesi, Mühendislik Fakültesi, Gıda Mühendisliği Bölümü, İzmir, Türkiye
}

Geliş / Received: 12.05.2021; Kabul / Accepted: 12.08.2021; Online bask1 / Published online: 20.09.2021

Yıldız Turp, G., Atalı, A. (2021). Et ürünlerinde tuzun fonksiyonlanı, tuz azaltılması amaciyla kullanılan ikame katk1lar ve etkileri. GIDA (2021) 46 (5) 1256-1269 doi: 10.15237/gida.GD21091

Yuldiz Turp, G., Atal, A. (2021 The functions of salt, substitute additives used for salt reduction and their effects in meat products. GIDA (2021) 46 (5) 1256-1269 doi: 10.15237/gida.GD21091

\section{ÖZ}

Et ürünlerinde kullanılan tuz, su tutma kapasitesini geliştirmesi, etin yumuşaklığını sağlaması, mikrobiyel koruyucu etki göstermesi, uçucu bileşiklerin etkinliğini arttrrması, renk pigmentinin gelişiminde rolü olması, lezzete katkısı sebebiyle önemlidir. Ancak yüksek miktarda tuz tüketimi birçok hastalığa neden olmaktadır. Tüketici bilincinin artması ve devlet otoritelerinin sağlı ile ilgili yaklaşımları gıda endüstrisinde tuz kullanımının azalılıasına yönelik araştırmaların artmasına neden olmaktadır. Et ürünlerinde tuz kullanımını azaltmaya yönelik çalışmaların başında; ürün formülasyonlarında tuza alternatif olabilecek katkıların, örneğin klorür tuzları, laktatlar, fosfatlar, polisakkaritler, deniz yosunları, lezzet artturıcilar, aminoasitler ve nükleotidler, süt mineralleri karışımlarının geliştirilmesi gelmektedir. Bu çalışmalarda temel amaç, tuzun sağladığı özellikleri üründe koruyacak katkılar geliştirerek sodyum tüketimini azaltmaktır. Bu çalısmada, et ürünlerinde tuz ikamesi olarak kullanılan katkılar ve bu katkıların ürün özellikleri üzerine etkileri derlenerek sunulmuştur.

Anahtar kelimeler: Et, et ürünleri, tuz, katkı maddeleri, sağl1k

\section{THE FUNCTIONS OF SALT, SUBSTITUTE ADDITIVES USED FOR SALT REDUCTION AND THEIR EFFECTS IN MEAT PRODUCTS}

\begin{abstract}
The use of salt in meat products is important, because salt increases the water retention capacity, provides tenderness of meat, has a microbial protective effect and contributes to taste. However, high consumption of salt causes many diseases. Increasing consumer awareness and health policies of state authorities lead to increase researches on reducing salt use in the food industry. The primary studies to reduce the use of salt in the meat industry have a content of the addition of additives such as chloride salts, lactates, phosphates, polysaccharides, seaweeds, flavor enhancers, amino acids and nucleotides, milk minerals mixtures that may be an alternative to salt in product formulations. The purpose of using salt substitute is to reduce sodium consumption by developing additives that will keep salt providing quality characteristics. This review includes the additives used in the meat products as salt substitutes and their effects on product properties.
\end{abstract}

Keywords: Meat, meat products, salt, additives, health

${ }^{*}$ Yazışmalardan sorumlu yazar / Corresponding author;

$\triangle$ gulen.yildiz.turp@ege.edu.tr

(c) (+90) 2323113038

悬:(+90) 2323114831

Gülen Yıldız Turp; ORCID no: 0000-0002-9318-3349

Ayşegül Atalı; ORCID no: 0000-0002-6563-3090 


\section{GİRİ̧̧}

Sodyum; hücre zarını koruyan, ince bağırsakta besinlerin emiliminde rol oynayan, asit-baz dengesini sağlayan, hücrenin dışındaki sıvının hacmini düzenleyen, kan basınc1 hacmini etkileyen ve dengeli alımı önemli olan bir mineraldir (WHO, 2020). Sodyum klorür $(\mathrm{NaCl})$, yaklaşık olarak \%40 sodyum ve $\% 60$ klorürden oluşmaktadır. İnsan vücudundaki sodyumun $\% 90$ 'ndan fazlası diyetteki yenilebilir tuzdan gelmektedir. Halk arasında "tuz" denildiğinde büyük çoğunlukla "sodyum klorür tuzu" ifade edilmektedir (Kamenik vd., 2017; Pretorius ve Schönfeldt, 2018; Europion Commission, 2020). $1 \mathrm{~g}$ sodyum klorür, $393.4 \mathrm{mg}$ sodyum'a eşittir (Bistola vd., 2020).

Tuz, gidalara lezzet vermesinin yanı sira gidaların raf ömrü süresince ürün güvenliğini koruması ve yapısal özelliklerini iyileştirmesi sebebiyle üretim proseslerinde ve tüketim tercihlerinde önemli bir yere sahiptir (Inguglia vd., 2017). Ancak aşı11 tuz tüketimi; kalp-damar hastalıkları, böbrek hastalıkları ve tansiyon bozuklukları başta olmak üzere felç, diyabet, osteoporoz, mide kanseri, obezite, multiple skleroz (MS), katarakt gibi birçok rahatsızlığa neden olmaktadır (Desmond, 2006; Mora-Gallego vd., 2016; Öztürk ve Garipağaoğlu, 2018; Pandian vd., 2018; Cappuccio vd., 2019).

Dünya Sağlık Örgütü (WHO) yetişkinler için günde $<5 \mathrm{~g}$ tuz (yaklaşı $<2 \mathrm{~g}$ sodyum) tüketilmesini önermektedir (WHO, 2012). Küresel tuz tüketimi önerilen seviyeye düşürülürse, her yıl yaklaşık 2,5 milyon ölümün önlenebileceği açıklanmıştır (WHO, 2020). Ancak küresel ortalamanın önerilen tuz tüketiminden çok yüksek olduğu ve ortalama 9-12 g/gün olduğu belirtilmektedir (He ve Macgregor, 2012; Erkoyun vd., 2016). Dünyada en yüksek tuz tüketimi Orta Asya'da (13.775 g/gün) görülmektedir (Powles, 2013). Avrupa'da kişi başına y1lda en fazla sodyum alımına sahip ülkeler, Çek Cumhuriyeti başta olmak üzere Doğu ve Orta Avrupa ülkeleridir. Almanya, Kıbrıs, Bulgaristan ve Letonya günlük en düşük tuz tüketimine sahip ülkeler arasında yer almaktadır (Kloss vd., 2015).
Türkiye'de tuz tüketiminin önerilenin üç katı olması Sağlık Bakanlığı'nı harekete geçirmiş ve "Türkiye Aşırı Tuz Tüketiminin Azaltılması Programı" nın başlamasına neden olmuştur. Tarım ve Orman Bakanlığı'nın da desteklediği bu program kapsamında, öncelikle ekmeklerin tuzu azaltılmıştır. Sonra peynir, salça, et ürünleri gibi işlenmiş gıdaların tuzunun azaltılması, toplu beslenme yapılan yerlerdeki menülerde tuz oranının düşürülmesi, masalardan tuzluğun uzaklaştırlması gibi önlemler alınmıştır ve alınmaya devam etmektedir (Sağlık Bakanlığı, 2016). Ülkemizde Türkiye Hipertansiyon ve Böbrek Hastalıkları Derneği tarafindan yapılan ve Türk Toplumunda Tuz Tüketimi Çalışması "SALTurk" adı verilen çalışmada, 2008 yılında ortalama $18 \mathrm{~g} /$ gün olan tuz tüketimi, yapılan yasal düzenlemeler ve bilinçlendirme faaliyetleri sayesinde 2012 yllında 15 g/gün'e düşmüştür (Öztürk ve Garipağaoğlu, 2018).

Türkiye'de ve dünyada tüketici bilincinin artması ve devlet otoritelerinin sağlık politikaları, g1da endüstrisinde tuz kullanımının azaltılmasına yönelik düzenlemelerin ve araştırmaların artmasını sağlamakla birlikte tuz tüketiminde istenilen seviyeye ulaşılamadığ1 görülmektedir. Günümüzde yetişkin insanların tükettikleri günlük ortalama tuz seviyesi tavsiye edilen miktarın çok üstündedir (Conroy vd., 2019). WHO üye devletlerinin, önerilen $<5 \mathrm{~g} /$ gün tuz tüketimi hedefine ulaşma yolunda 2025 yllina kadar tuz tüketimlerini $\% 30$ azaltma kararları bulunmaktadır (Chestnov, 2013).

Az miktarda tuz içeren taze gidalar (et, sebze ve meyve gibi) işlem gördügünde tuz seviyesi önemli oranda artmaktadır (Inguglia vd., 2017; USDA, 2018). Endüstriyel olarak işlenmiş gıda maddeleri, gelişmiş ülkelerde tuz alımının yaklaşık \% $75^{\prime}$ ini oluşturmaktadır. Sodyum alımına en fazla katkıda bulunan gıdalar; isslenmiş etler (\%18), ekmek ve unlu mamuller (\%13), süt ürünleri (\%12) ve soslardır (\%11) (Aaslyng, Vestergaard ve Koch, 2014; Kamenik vd., 2017).

Bilimsel çalışmalar 1şı̆̆ında tüketiciler ve et endüstrisi daha az sodyum içeren daha sağlıklı bir diyetin yararları hakkında bilinçlenirken, az tuzlu 
et ürünlerine olan talep birçok ülkede artmaktadır. İşlenmiş et ürünlerinde tuz azaltma çalışmaları 1980’lerde başlamıştır. Ancak et ürünlerinde tuz azaltma, gida endüstrisi için büyük bir zorluktur. Tuz, ürüne lezzet vermesinin yanı sıra ürün güvenliğini ve raf ömrünü korumaya yardımc1 olmaktadır ve et proteinlerinin yapısını etkileyerek işlenmiş et ürünlerinin istenilen özelliklerde üretilmesi üzerinde etkisi bulunmaktadır (Bingöl ve Bostan, 2012; Inguglia vd., 2017; Conroy vd., 2019).

Et endüstrisinde tuz kullanımını azaltmaya yönelik çalışmaların başında; tuza benzer kalite sağlama rolünü gerçekleștirebilecek alternatif katkıların et ürünlerinin tuzluluk lezzetini etkilemeden ürün formülasyonlarına ilavesi gelmektedir. Tuz ikamesi katk1 maddelerinin kullanımı ile tuz tüketiminde yaklaşık \%30-50 oranında azalma öngörülmektedir (CTAC, 2009).

Bu çalışmada; tuzun et ve et ürünleri üzerindeki fonksiyonları ve et ürünlerinde tuzun kullanımını azaltmak amaciyla ilave edilen katkı maddeleri ve bu katk1 maddelerinin et ve et ürünlerine etkileri derlenmiştir.

\section{TUZUN ET ÜRÜNLERİ ÜZERİNDEKİ ETKILERİ}

Et ve et ürünleri, yüksek protein değeri, esansiyel amino asitleri, esansiyel yağ asitleri, B-kompleks vitaminleri, demir ve çinko gibi mineralleri bulundurmasindan dolayı insan beslenmesinde çok önemli bir yere sahiptir (Riberio vd., 2019). Ancak işlenmiş etler, diyetimizde başlıca tuz kaynaklarından biridir. Et ürünlerinin muhafazasında antik çağlardan beri kullanılmakta olan tuz, aynı zamanda modern et endüstrisinde de en çok kullanılan katkı maddelerinden biridir.

Tuz, antibakteriyel bir bileşiktir. Tuzun mikroorganizmalara karşı antibakteriyel etkisi, et ürünlerine uygulanan diğer antimikrobiyel bileşenler ve işlemlerle desteklenmektedir (Gökalp vd., 2012). Tuzun su aktivitesini düşürmesi ve mikroorganizmalar üzerine etkili olan ozmotik basınç oluşturan iyonlarının varlığı işlenmiş etlerin raf ömrünü arttırmaktadır (Weiss vd., 2010). Tuz aynı zamanda kas dokusundaki oksijenin çözünürlügünü azaltarak ve bakteriyel proteolitik enzimlerin aktivitesini limitleyerek de bakteri çoğalımını engelleyebilmektedir. Tuzun, bakteriler üzerinde yüksek toksik etkisi olmasına rağmen maya ve küflere karşı etkisi sınırlıdır (Gökalp vd., 2012).

Tuz, et ürünlerine karakteristik lezzetini veren önemli bir bileşendir. Bu kapsamda tuzun işlenmiş et ürünlerinin tipik lezzetini arttırdığ belirlenmiştir (Weiss vd., 2010). Et ürünlerinde algilanan tuzluluğun sebebi $\mathrm{Na}^{+}$ve $\mathrm{Cl}^{-}$ iyonlarından kaynaklanmaktadır. Lezzet yoğunluğu, et ürünlerinde tuzun konsantrasyonuna bağlıdır. Et ürünlerini işleme sırasında tuz, proteoliz ve lipolizi etkileyerek lezzete katkısını arttırmaktadır. Sodyum klorür oranının değiştirilmesi, gida matrisinin yapısını değiştirmektedir. Bu durum gıda matrisinin uçucu ve uçucu olmayan bileşenlerini ve aralarındaki fizikokimyasal etkileşimler yoluyla lezzet bileşiklerinin salınım kinetiğini etkilemektedir (Taylor vd., 2018; Flores, 2018; Thomas-Dangui vd., 2019; Campo vd., 2020).

Tuzun et ürünlerinde \%1.5-2.5 arasinda bulunması, myosin proteinini çözündürerek et ürünlerinin su tutma kapasitesinde ve etin yumuşaklı̆̆1 gibi dokusal özelliklerinin gelişmesinde önemli bir rol oynamaktadır (Guo vd., 2020). Tuz, etin gevrekliğini su tutma kapasitesinde artıs sağlayarak ve jelatinizasyonla arttırmaktadır (Zheng vd., 2019). Tuz eklendiğinde ve proteinler çözündügünde, et hamurlarının viskozitesi artar, proteinler protein ağını oluşturmak üzere bir interaksiyona girerler, böylece stabil bir emülsiyon oluşur (Desmond, 2006; Weiss vd., 2010). Düşük tuzlu et ürünleri ile ilgili temel problem, esas olarak düşük iyonik mukavemet altında myofibriler proteinin düşük çözünürlüğü nedeniyle pişme verimi, sululuk ve dokunun bozulmasıdır (Tamm, 2016; Akgün vd., 2018; Guo vd., 2020).

Et ürünlerinin rengi, renk pigmentleri ile kürleme maddelerinin reaksiyonuna bağlıdır. Sodyum klorür tuzunun, et ürünlerinde meydana gelen renk pigmentinin gelişiminde rolü bulunmaktadır. Klorür iyonunun, kürlenmiş etlerde nitritten nitrik 
oksit oluşum oranını artırarak kürlenmiş renk oluşumunu hızlandırdığı bildirilmiştir (Tarte, 2009; Pinna vd., 2020).

Et ve et ürünlerindeki suyun değişimi ve yayllımı, ürünün görünüm, gevreklik, sertlik, sululuk gibi kalite özellikleri ve mikrobiyolojik stabilitesinde önemli bir etkiye sahiptir. Su molekülü kılcal damarlar ile myofibriller arasindaki boşlukta tutulmakta ve bu boşluktaki artma veya azalma su tutma kapasitesini belirlemektedir. Tuz, $\mathrm{pH}$ değişimini sağlamakta ve proteinlerin çözünmesi gerçekleşmektedir. $\mathrm{pH}$ değeri, tuzlu ve kuru et ürünlerinde su kayb1 ve su tutma kapasiteleriyle ilişkilendirilmektedir. Tuz ilavesi, etin su aktivitesini ve $\mathrm{pH}$ değerini düşürmekte, mikrobiyel koruyucu etki oluşmaktadır (Inguglia vd., 2017; Vidal vd.,2019).

Sodyum klorürün pro-oksidant aktivitesi; hücre membranı bütünlügüne zarar vererek okside ajanların lipid substratlarına ulaşmasını kolaylaştırması, hem proteinleri gibi demir içeren moleküllerden demir iyonlarının serbest kalması, antioksidan enzimlerin aktivitelerinin engellenmesi nedeniyledir (Mariutti ve Bragagnolo, 2017).

Yapılan bir çalışmada, kavurma üretiminde farklı oranlarda kullanılan tuzun, depolama süresince üründe kalite ve besin değeri kaybına neden olan furozin ve ileri glikasyon ürünlerinden biri olan $\mathrm{N} \varepsilon$-karboksimetil-lisin oluşumu üzerine etkileri incelenmiştir. Üründe $\% 1.5$ ve $\% 2$ oranlarında tuzun, $\% 1$ tuz kullanımina göre daha yüksek furozin içeriğine neden olduğu, bunun yanında farklı tuz oranlarının Ne-karboksimetillisin oluşumu üzerinde önemli düzeyde etkili olmadığı belirlenmiştir (Bayrak vd.,2021). Farklı pastırma tiplerinde iki farklı tuz oranı ( $\% 3$ ve $\% 5)$ kullanımının ürün yağ asidi kompozisyonu üzerine etkilerinin incelendiği bir çalışmada, $\% 5$ tuz içerikli örneğin, \%3 tuz içerikli örneğe kıyasla daha yüksek oleik asit oranına sahip olduğu, bunun yanında palmitik, stearik, oleik ve linoleik yağ asitleri üzerinde pastırma çeşidi $\mathrm{x}$ tuz oranı interaksiyonunun önemli olmadığı belirlenmiştir (Kabil vd., 2020).

\section{ET ÜRÜNLERİNDE TUZA İKAME OLARAK KULLANILAN KATKI MADDELERİ}

\section{Klorür Tuzlarının Kullanımı}

Sodyum klorürün $(\mathrm{NaCl})$ et ürünlerinde kullanımının azaltılmasi amaciyla sodyumun, kalsiyum, magnezyum ve potasyum gibi klorür tuzlarıyla değiştirilmesine yönelik çalışmalar yapılmaktadır. Ancak klorür tuzları, et ürünlerinin lezzeti üzerine olumsuz etkiler oluşturabilmektedir. Klorür tuzlarının bu etkilerini azaltmak amaciyla lezzeti geliştirecek katkılar ile birlikte kullanımları üzerine çalışmalar yürütülmektedir (Inguglia vd., 2017).

Mineral tuzlarının, özellikle istenmeyen mikroorganizmaların gelişmesini kontrol etmede etkili olduğu belirtilmiştir (Mitchell, 2019). Et proteinlerinin jelleşmesi sırasında iki değerlikli katyonların (kalsiyum ve magnezyum) ve tek değerlikli katyonun (potasyum) et proteinlerinin işlevselliğini arttırdığ1 belirtilmektedir. Düşük tuz/sodyum içeren gidalarda sodyum klorür alternatifi olarak en çok kullanılan katkı maddesi potasyum klorürdür (Bidlas ve Lambert, 2008). WHO, potasyum mineralinin sağlık faydaları sebebiyle >3.5 g/gün alımını önermektedir. Günlük potasyum alımının sodyum alımından fazla olması gerektiği belirtilmektedir. Ancak potasyumun fazla alımının böbreklerden atılımı zorlaştırması sebebiyle kullanımına da dikkat edilmesi gerekmektedir (Luta vd., 2018).

Potasyum klorürün tek başına sodyum klorürün alternatifi olarak kullanımı acı ve metalik bir tat vermesi nedeniyle ancak düşük oranlarda gerçekleşebilmektedir. Artan kullanım miktarlarında tadın iyileştirilmesi amacıyla lezzet arttırıcilar (genellikle MSG, maya ekstraktları veya umami tat veren aromalar) veya maskeleme ajanları (trikalsiyum fosfat; sitrik asit; magnezyum sülfat; potasyum iyodür; tartar kreması) kullanılmaktadır. Diğer katkı maddeleri ile kullanımında $\% 50$ potasyum klorür $(\mathrm{KCl})$ kullanımı mümkün olmaktadır. Sodyumun $\% 50$ oraninda azaltılması amaciyla $\% 30-50 \mathrm{KCl}$ ve $\% 5$ 20 lezzet arttırıcılar formülasyonlarda yer alabilmektedir. Sodyum klorürün 1.5 katı kadar potasyum klorürün mikrobiyel gelişme üzerinde 
benzer bir etkiye sahip olduğu belirlenmiştir (CTAC, 2009; Cepanec vd., 2017; Mitchell, 2019).

PuraQ ${ }^{\circledR}$ Arome NA4; şeker, organik asit tuzları ve aroma karışımının fermantasyonundan üretilmektedir ve potasyum klorürün kullanımını arttırmak amaciyla ticari lezzet arttırıcı olarak kullanilmaktadır. PuraQ®Arome NA4 eklenen hamburger köftesinin mikrobiyolojik, duyusal ve fiziko-kimyasal özellikleri incelenmiştir. $100 \% \mathrm{NaCl}, \quad 50 \% \mathrm{NaCl}+50 \% \mathrm{KCl}+$ PuraQ ${ }^{\circledR A}$ Arome NA4 ve $40 \% \mathrm{NaCl}+60 \% \mathrm{KCl}+$ PuraQ ${ }^{\circledR}$ Arome NA4 formülasyonuyla hazırlanan hamburger köftelerinde mikrobiyolojik ve fizikokimyasal özelliklerde belirgin bir farkllık tespit edilmemiştir. $\% 50 \mathrm{NaCl}$ ile $\% 100 \mathrm{NaCl}$ kullanılan köftelerin genel beğeni puanlarının yakın olduğu gözlemlenmiştir. $\% 60 \mathrm{KCl}$ kullanılan köfte formülasyonunda potasyum klorürden kaynaklanan hafif acimsı tat hissedilirken genel beğenide yüksek bir düşüş belirlenmemiştir (Vidal, 2020).

$\mathrm{KCl}, \mathrm{CaCl}_{2}$, ve $\mathrm{MgCl}_{2}$ 'ün kısmi olarak sodyum klorür ile yer değiştirmesinin myofibriler proteinlerin jel yapısına etkilerinin incelendiği bir araştırmada en yüksek tuz içeriğine sahip örneklerde, jel yapısının homojen ve yüksek kalitede olduğu belirlenmiştir. Ayrıca $\% 25 \mathrm{KCl}$ ikamesinin diğerlerine göre daha iyi sonuçlar verdiği ve jel mukavemeti ile birlikte su tutma kapasitesini arttırdığ1 gözlemlenmiştir (Ge vd., 2020). Potasyum klorürün ac1-metalik tadını azaltmak amacıyla kristal yapısının değiştirilmesi esasına dayanan modifiye edilmiş potasyum klorür kullanılabilmektedir. Yapılan bir çalısmada sosis üretiminde, modifiye potasyum klorürün yalnızca potasyum klorür kullanımına kıyasla örneklerin duyusal değerlendirme sonuçlarını olumlu etkilediği belirlenmiştir (Stanley vd., 2017).

İstenilen tuzluluk tadı, daha düşük sodyum içerikli bazıları ticarileştirilmiş olan tuz karışımları ile elde edilebilmektedir. Bunun bir örneği Pansalt'tır. Pansalt, patentli bir $\mathrm{NaCl}$ ikamesidir. Pansalt'ın formülasyonunda sodyumun yaklaş1k \%50'si potasyum klorür, magnezyum sülfat ve esansiyel amino asit l-lisin hidroklorür ile yer değiştirmiştir. Amino asidin kullanımı, $\mathrm{NaCl}$ ikame edicisinin tuzluluğunu arttırmaktadır ve potasyum ve magnezyumun tadinı maskelerken insan vücudundan sodyum atılımını artırmaktadır. Pansalt içeriğinde fosfatlı çözeltilerde çözünmeyen $\mathrm{Mg}^{+2}$ iyonlarının bulunmasından dolay1, fosfat eklenmemiş et ürünleri için daha uygundur (Desmond ve Vasilopoulos, 2019). Malabar firması tarafindan et ürünlerinde tuz ikamesi olarak kullanılmak üzere üretilen "LowSo Salt", modifiye edilmiş potasyum klorür ve pirinç unu içermekte ve salamda $\% 25$ oranında tuz azaltılmasını sağlamaktadır (Inguglia vd., 2017). Wixon firması tarafindan üretilen patentli KcLean Salt ${ }^{\circledR}$, potasyum klorür ve sodyum klorürün bir karışımı olup, tuz kullanımında $\% 50$ ye varan bir azalma sağlamaktadır. Potasyum klorür içerikli Kalimer ise Kali firması tarafindan üretilmekte ve ürünlerde sodyum içeriğini $\% 30$ oranında azaltmaktadır. Benzer şekilde potasyum klorür ana bileşenli Salt Trim, Wild Flavors firmas1 tarafindan üretilmekte ve ürünlerde $\% 50$ oranina kadar sodyum azaltılmasinı sağlayabilmektedir (CTAC, 2009; Inguglia vd., 2017).

Geleneksel Türk et ürünleri arasinda olan pastırmada tuz içeriği yaklaşık $\% 5$ civarındadır. Yapılan bir çalışmada, pastırma üretiminde $\mathrm{NaCl}$ miktar1 \%50 oraninda azaltılarak, yerine $\mathrm{KCl}$ ve $\mathrm{CaCl}_{2}$ tuzları kullanılmıstır. Elde edilen pastırma örneklerinin fiziksel, kimyasal ve mikrobiyolojik özellikler bakımından kabul edilebilir düzeyde olduğu, en uygun ikame maddesinin $\mathrm{KCl}$ olarak belirlendiği bildirilmiştir (Ekmekçi, 2012). Bununla birlikte 1 sil işlem görmüş sucuk örneklerinin koku ve tat puanlarını azaltması nedeniyle KCl'nin ikame seviyesinin \%50'yi geçmemesi gerektiği bildirilmiştir (Oral ve Kaban, 2021). Ayrıca 1sıl işlem görmüş sucukta KCl'nin artan oranlarının üründe oksidasyonu arttırdığı ve pH değerini azalttığı yapılan başka bir çalışma ile ortaya konulmuştur (Bayraktar, 2017). Sucuk üretiminde sodyum klorür yerine farklı oranlarda $\mathrm{KCl}, \mathrm{MgCl}_{2}, \mathrm{CaCl}_{2}$ tuzlarının kullanıldığı ve bu tuz karışımlarının olgunlaştırma sırasındaki etkilerinin incelendiği bir çalışmada, en düşük Micrococcus/ Staphylococcus sayısı ve su aktivitesi değerinin $\mathrm{NaCl}$ kullanılan kontrol örneğinde belirlenmiştir (Şimşek, 2016). 


\section{Laktatların Kullanım}

Laktik asit ve tuzu olan laktatlar, tüketiciler için sağlık riski oluşturmamaları, ürünün renk, lezzet ve doku gibi duyusal özelliklerini iyileştirmeleri ve ayrıca ürünlerin mikrobiyolojik güvenilirliklerini arttırmalar1 nedeniyle katk1 maddesi olarak önerilmektedir. Sodyum laktat, sodyum klorüre oranla \%50 daha az sodyum içermektedir. Potasyum ve sodyum laktatlar et ve kanatli endüstrisinde antimikrobiyel ajanlar olarak yaygin şekilde kullanılmaktadır. Sodyum ve potasyum laktat tuz oranı azaltılmış et ürünlerinde denenmiş ve belirli bir tuzluluk seviyesini korudukları tespit edilmiştir (Bingöl ve Bostan, 2012). Potasyum laktat, tuz benzeri işlevselliğe ve güçlü su bağlama özelliğine sahip olduğu ve ayrıca antimikrobiyel özellik gösterdiği için tuz ikamesi olarak tercih edilebilmektedir. Bununla birlikte, Potasyum laktat, genellikle potasyum bazlı ürünlerle ilişkilendirilen ac1 tat verici maddeler içermemektedir (Choi vd., 2014). Yapılan bir çalıșmada sosis üretiminde tuzun $\% 40$ oranında potasyum laktat ile ikame edilmesi sonucunda doku özelliklerinden sertlikte azalma olduğu tespit edilmiştir (Gelabert vd., 2003). Kalsiyum laktatın içerdiği kalsiyum; kemik sağlı̆̆1, diğer fizyolojik fonksiyonlar ve enzimatik reaksiyonlar sebebiyle insan diyetinde en önemli minerallerden biridir (Gore vd., 2019). Ayrica et ürünlerinde oksidasyonu geciktirerek renk stabilitesini sağlamaktadır (Kim vd., 2019). Sertleştirici ve kabartma ajanı olarak kullanılan kalsiyum laktat içeren karışım, Harbin sucuğuna ilave edildiğinde $\mathrm{NaCl}$ oranının \%30 azaldığı, lipit ve protein oksidasyonunun geciktiği görülmüştür (Wen vd., 2019).

\section{Fosfatların Kullanımı}

Fosfatlar genellikle su tutma kapasitesini ve pişme verimini arttırmak için et ürünlerinde kullanılmaktadır. Fosfatlanın işlevselliği tuz ilavesinden büyük ölçüde etkilenmektedir ve bu bileşenler sinerjistik etki etmektedir. Yapılan bir çalışmada, sodyum difosfat ve tetra potasyum profosfatın bologna tipi sosis ve jambon üretiminde tuz azaltılması amaciyla kullanılabildiği belirlenmiștir (Ruusunen vd., 2002). Sodyum fosfat $\% 30$ sodyum içeriğine sahip olması nedeniyle et ürünlerinde sodyum miktarını arttıran bir katk1 maddesidir. $\mathrm{Bu}$ nedenle tuz ikamesi olarak sodyum fosfat yerine potasyum fosfat kullanımı önerilmektedir. Sodyum difüzyon oranlarının sinırlandirılmasi yoluyla sodyum azaltma stratejisi uygulanan bir çalışmada, hindi küplerinde yüksek moleküler ağırlıklı sodyum tuzlarının etkisi incelenmiştir. Çalışmada, sodyum klorürden $(35 \mathrm{~g} / \mathrm{mol})$ daha büyük moleküler ağırlıklı sodyum anyon tuzu olan disodyum fosfatın $(95 \mathrm{~g} / \mathrm{mol})$ sodyum klorür ile 50:50 (ağırlıkça) karışımının kullanılması durumunda üründe $\% 20$ daha düşük sodyum içeriğine ulaşıldığ1 saptanmıştır. Duyusal değerlendirme sonucunda ürünün doku özelliklerinin geliştiği ve genel kabul edilebilirliğinin yüksek olduğu belirlenmiştir (Pandya vd.,2020).

\section{Polisakkaritlerin Kullanımı}

Polisakkaritler, monomerlerin glikozit bağlar yoluyla birleşmesiyle hayvan, bitki veya mikroorganizmalardan üretilen makromoleküllerdir (Ruusunen vd., 2003) Sodyum nitrat, karboksimetil selüloz ve karragenan karışımı ilave edilen düşük tuz içerikli sosislerin pişme kaybının azaldığ1, lezzet yoğunluğu ve sululuğunun arttı̆̆1 belirlenmiştir (Kaur, 2019). Yapılan başka bir çalışmada, tavuk ürünlerinde tuz ve polifosfat içeriğinin azaltılmasında yulaf $\beta$-glukanın jel oluşturma kabiliyetinden yararlanılarak, yüksek basınç işleminin kullanılabileceği sonucuna varılmıştır (Omana vd., 2011).

\section{Deniz Yosunlarının Kullanımı}

Deniz yosunu; polisakkaritler, uzun zincirli çoklu doymamış yağ asitleri (PUFA), protein, karotenoidler, fenolik bileşikler, vitaminler ve mineralleri içeren önemli bir gıdadır (Gullon vd., 2020). Dolasiyla antioksidan, antihiperlipidemik, antihipertansif ve antikanser özellikleri sebebiyle sağlık açısından faydalıdır. $\mathrm{AB}$ tarafindan finanse edilen TASTE Projesi ile, yenilebilir alglerin farklı gidalarda $\mathrm{NaCl}$ nin yerini alma potansiyeli araştırılmaktadır. $\mathrm{Na}, \mathrm{Ca}, \mathrm{Mg}, \mathrm{P}, \mathrm{Mn}, \mathrm{K}, \mathrm{I}, \mathrm{Fe}$ ve Zn gibi yüksek mineral içeriği, deniz yosunlarının işlenmiş ette tuz ikame maddesi olarak kullanımına imkan vermekte, ayrıca et ürünlerinde bulunmayan diğer minerallerin alımını arttırmaktadır. Bunun yanında deniz yosunları, hipertansiyon ve kardiyovasküler hastalık 
risklerini önlemek için uygun bir özellik olan düşük $\mathrm{Na} / \mathrm{K}$ oranına sahiptir. Deniz yosunlanı et ürünlerinde tuz miktarını azaltma, besin değerini arttırma, pişme kaybını azaltma, duyusal özellikleri iyileştirme ve fiziko kimyasal yapıyı geliştirme amaçlı kullanılabilmektedir. Deniz yosunu özütü içeren AlgySalt ${ }^{\circledR}$, PureSea ve Seagreens ticari ürünleri tuz ikamesi olarak piyasada bulunmaktadır. Yapılan bir çalışmada, sosis üretiminde tuz ikamesi olarak AlgySalt ${ }^{\circledR}$ ile $\mathrm{KCl}$, $\mathrm{CaCl}_{2}$ ve $\mathrm{MgCl}_{2}$ karışımı etkileri karşılaştırılarak incelenmiştir. Her iki formülasyon da $\mathrm{NaCl}$ içeren kontrol örneklerine kıyasla benzer mikrobiyolojik koruyucu etki göstermiştir. AlgySalt@ ile formüle edilen et ürünlerinde istenen renk, doku ve sululuk elde edilmiştir (Triki vd., 2017; Gullon vd., 2020).

\section{Lezzet Arttırıcıların Kullanımı}

Lezzet arttırıcılar, gidanın tadını doğrudan değiştirmeden tat ve koku algisinı arttıran maddelerdir. Bunlar ağız ve boğazdaki duyu merkezlerini aktifleştirerek tuzun azaltılması sonucunda ortaya çıkan lezzet kaybını geriye kazanmaya yardımcı olmaktadırlar. Bazı lezzet arttırıcılar umami tadını alg1layan reseptörleri uyararak gidanın lezzet dengesini değiştirmektedir ve bu tat, düşük sodyumlu ürünlerin yavan lezzet profilini iyileştirmektedir. Maya özütü, hidrolize bitkisel protein (HVP), monosodyum glutamat (MSG), glutamik asit, nükleotid içeren bileşenler gibi gida bileşenleri umami karakteri ortaya çıkarmaktadır (Inguglia vd, 2017; Sağlık Bakanlığ1, 2019).

Glutamik asit, umami lezzet veren bir bileşiktir ve protein bakımından zengin mantar, bezelye, domates, mısır ve sığır eti gibi gidalarda doğal olarak bulunmaktadır. Glutamik asit ayrıca pekmez fermantasyonu veya bitkisel proteinin hidrolizi yoluyla ticari olarak üretilmektedir. Monosodyum glutamat elde etmek için sıklıkla sodyum ile birleştirilmektedir (CTAC, 2009; Chapman ve Speirs, 2014). Glutamik asit ve sodyumun bir kombinasyonu olan MSG, işlevselliği, ucuz olması, kolay üretilebilir olması ve düşük konsantrasyonda kullanılabilme avantajları sebebiyle en çok kullanılan lezzet arttırıcıdır. MSG daha önceleri alg gibi protein bakımından zengin kaynaklardan elde edilirken, günümüzde endüstriyel fermantasyon yöntemiyle melastan üretilebilmektedir. MSG tuzdan üç kat daha az sodyum içermektedir ve sodyum miktarının \%20-40 oranında azaltılmasına olanak sağlamaktadır. Tuzlu yiyeceklerin lezzetini ve algilanan tuzluluğunu arttırmaktadır ve umami tat reseptörlerini uyaran tuzlu bir tat vermektedir (Henney, 2010; Mitchell, 2019; Sağlık Bakanlı̆̆1, 2019). Ancak MSG'nin hiperaktivite, obezite, mide rahatsızlıkları, migren gibi sağlık problemlerine yol açma olasilığ nedeniyle kullanımından kaçınılmaktadır. Bu nedenle gıda üreticileri maya özütleri gibi alternatif doğal lezzet arttırıcılarını araştırmaya yönelmektedirler (Kilcast ve Ridder, 2007; Henry-Unaeze, 2017; Mitchell, 2019).

Maya ekstrakt1; peptitler, nükleotidler, glutatyon, $\mathrm{B}$ vitaminleri ve amino asitlerce zengin olup lezzeti iyileştirmek için kullanılan doğal bir maddedir. Maya ekstrakt1, endüstriyel gıda fermantasyonu ile birçok formda üretilebilmektedir. Maya ekstraktında uçucu olan veya olmayan aromayı aktifleştiren bileşiklerin çoğu 1sısal işlem sırasında üretilmektedir ve lezzeti arttırmaktadır. Genellikle "zzgara veya kızarmış" etki oluşturan bir tat sağlamaktadır. Tuzlu ve umami etki sağlamak için kullanılmaktadır. Springer® Maya Ekstraktı, ticari olarak satılan maya ekstraktına örnek verilebilir (Alim vd., 2018; Vidal vd., 2019).

Hidrolize bitkisel protein, yüksek seviyelerde glutamat içeren bir lezzet arttırıcıdır. Hafif et lezzeti oluşturmaya katkıda bulunması sebebiyle et suyu, çorba, sos ve et ürünlerinde kullanılan baharat karışımlarında özellikle tercih edilmektedir. Toz, macun veya siv1 halde bulunabilmektedir (CTAC, 2009; Chapman ve Speirs, 2014; Mitchell, 2019).

\section{Aminoasitlerin ve Nükleotidlerin Kullanımı}

Myosinin çözünürlüğünü arttırmak, tuzu azaltılmış et ürünlerinin üretiminde önemlidir. Histidin, L-arginin ve besin değeri yüksek esansiyel bir amino asit olan L-lisin düşük iyonik güçte olan myosinin çözünürlüğünü artırmaktadır. L-arginin ve L-lisin emülsiyon stabilitesini ve su tutma kapasitesini arttırmakta, jel yapisını 
iyileştirmekte, ayrıca pişme kaybını azaltmaktadır (Li vd., 2019). Et ürünlerinde $\mathrm{NaCl}$ içeriğinin kısmen $\mathrm{KCl}$ ile yer değiştirilmesi durumunda lisinin üründe bir lezzet arttırıcı olarak görev yaptığı ve $\mathrm{KCl}$ kaynaklı acı-metalik tadın azaldığı belirlenmiştir (Vidal vd.2020). Yeniden formüle edilerek sodyum içeriğinde $\% 35.8$ oranında azalma sağlanan jambona \%0.8 L-lisin ilavesinin su tutma kapasitesini artırdı̆̆1, dokusal özellikleri iyileştirdiği ve duyusal değerlendirme ile belirlenen genel kabul özelliğini olumsuz yönde etkilemediği gözlemlenmiştir (Guo vd., 2020).

Umami tat, inosin-5-monofosfat (IMP), guanosin-5-monofosfat (GMP) ve adenosin-5amonofosfat (AMP) gibi serbest nükleotitlerin varlığ1 ile arttırllabilmektedir. Nükleotidler, MSG ile sinerji halinde umami tadın yoğunluğunu yükseltebilmekte ve lezzeti geliştirebilmektedirler. $\mathrm{Bu}$ nükleotidlere örnek disodyum guanilat, disodyum inosinat, kalsiyum inosinat, disodyum ribonükleotid, kalsiyum ribonükleotid verilebilir (Hoppu vd., 2017; Mitchell, 2019). Marlow Foods firmasinın ürünü olan Mycoscent, ribonükleotitlerden oluşan bir mikoprotein türevidir. Aroma geliştirici olarak belirtilmektedir. Mycoscent'in tuzlu tat verebilme işlevi, gıdanın içeriğindeki tuzun tadını artırması şeklinde gerçekleştiği için, tuz ile kombinasyonu gereklidir (Parniakov vd., 2020).

\section{Aromatik Bitkiler ve Baharatların Kullanımı}

Aromatik bitkiler ve baharatlar, lezzet yoğunluğunu artırdıklarından dolayı tuz azaltılmasında önemli bir rol oynamaktadırlar. Tuzu azaltılmış et ürünlerine kırmızı biber, dereotu, nane, kekik, fesleğen, soğan, sarımsak, maydanoz, kereviz, kişniş, kekik, limon, biberiye, kekik, köri ve isırgan otu ilavesi lezzeti geliştirmektedir. Aromatik bitki ve baharatların et ürünlerinde yapısal fonksiyonlarının azlığ1 sebebiyle, düşük sodyum içerikli veya sodyum dışındaki tuzların baharatlarla karışımları tercih edilmektedir. Aroma, lezzet arttric1 ve renklendirici eklenen azaltılmış sodyum klorürden oluşan formülasyonların ticari başarılarının yüksek olduğu gözlenmektedir (Parniakov vd., 2020; Taladrid vd., 2020).
Farklı Yapıda Sodyum Klorür Tuzu Kullanımı Tuz mikroküreleri olarak patentli üretilen SodaLo ${ }^{\circledR}$ içeriğinde, standart deniz tuzu kristallerinden dönüşen kristal mikroküreler bulunmaktadır. Bu mikrokürelerin içi boştur ve normal tuz kristallerinden çok daha küçüktür (parçacık büyüklügü 20-30 $\mu \mathrm{m}$ ). Soda-Lo ${ }^{\circledR}$ gida matrisinde mükemmel bir dağılım sağlayarak, sodyum benzeri tat oluşturmakta ve sodyum azaltılmasına imkân vermektedir. Jambon, hindi göğüs eti ve sosiste Soda-Lo ${ }^{\circledR}$ kullanılan bir çalışmada sosiste $\% 30.07$, jambonda $\% 21.93$ ve hindi göğüs etinde $\% 10$ sodyum azaltılması sağlandığı belirtilmiştir (Raybaudi-Massilia vd., 2019).

Yapılan bir çalşmada iki boyuta indirilen tuz kristallerinin sığır köftesinde tuzluluk hissini azaltmadığı ve başarılı bir şekilde sodyum miktarının azaltılması amacıyla kullanılabileceği sonucuna varılmıştır (Gaudette vd., 2019).

\section{Süt Mineralleri Karışımı Kullanımı}

Süt mineralleri; süt ve peynir üretimi yapan işletmelerin yan ürünleridir. Süt mineralleri, kalsiyum, magnezyum, sodyum ve potasyum gibi minerallerden oluşmaktadır ve peynir altı suyu, et ve balık ürünlerinde doğal bileşenler olarak ve tuz ikame maddeleri olarak kullanilabilmektedir. Potasyum açısından zengin süt mineralleri, sosislere eklendiğinde iyi bir $\mathrm{Na}$ : K oranı sağlayabilmektedir ve tuzluluğu artırabilmektedir (Engeloug vd., 2017). Yapılan bir çalışmada mezgit balığ1 pudinginde süt minerallerinin kullanımının et proteinlerinin çözünürlügünü ve su tutma kapasitesini arttırdığ1 ve tuzluluk tadını etkilemeden sodyum miktarında azalma sağladığ1 belirlenmiştir (Greiff vd., 2015). Sütten elde edilen konsantre mineral karışım, acı tat vermeden lezzeti arttırıcı olarak kullanılmaktadır. Armor Proteines firmasi tarafindan üretilen Lacto Optitaste ürününün $\% 25$ oranında tuz kullanımını azalttığı, ayrıca temiz etiket olarak da tercih sebebi olabildiği belirtilmiştir (Chapman ve Speirs, 2014).

\section{SONUÇ}

Et ürünlerinde önemli fonksiyonları bulunan tuzun kullanım miktarının azaltılması amaciyla çok sayıda katkı maddesi denenmiştir. Potasyum ve kalsiyum gibi klorür tuzlarının kullanımı 
üzerine yapılan çalışmaların en kapsamlı çalışmalar olduğu, ancak bu katkı maddelerinin et ürünlerinin duyusal ve fiziksel bazı kalite özelliklerinde olumsuz etkiler oluşturabildiği gözlemlenmiştir. Klorür tuzlarının lezzet arttırıcı katkılar ile birlikte et ürünlerinde kullanılması durumunda ise olumlu sonuçlar elde edilebildiği belirlenmiştir. Bunun yanında yapılan çalışmalarda et ürünlerinde tuz ikamesi olarak laktatların, aminoasitlerin, nükleotidlerin, polisakkaritlerin, deniz yosunlarının, aromatik bitki ve baharatların başarı ile kullanılabildiği, bu alanda üretilen bazı tuz ikamelerinin ticarileştirilerek endüstride kullanımına başlandığı görülmektedir. Son yıllarda umut vadeden çalışmaların bir kısmını da süt minerallerinin ve mikrokürelerinin yapisal özellikleri değiştirilen sodyum klorürün et ürünlerinde tuz ikamesi olarak kullanıldığ çalışmalar oluşturmaktadır. Ancak halen farklı tipte et ürünlerinin duyusal, fonksiyonel ve mikrobiyolojik özelliklerinde, tuzun gösterdiği fonksiyonları gerçekleştirebilecek katkı arayışına yönelik, ayrıca farklı katkıların sinerjistik özelliklerinin de incelendiği daha fazla araştırmaya ihtiyaç bulunmaktadır.

\section{ÇIKAR ÇATIŞMASI BEYANI}

Yazarlar, bu makale ile ilgili olarak başka kişiler ve/veya kurumlar arasında çıkar çatışması olmadığını beyan etmektedir.

\section{YAZAR KATKILARI}

Tüm yazarlar makalenin yazılmasinda ve yayınlanmasında katkı sağlamışlardır. Makalenin hazırlanmasında başka kişi ve/veya kurumların katk1sı yoktur.

\section{KAYNAKLAR}

Aaslyng, M. D., Vestergaard, C., Koch, A. G. (2014). The effect of salt reduction on sensory quality and microbial growth in hotdog sausages, bacon, ham and salami. Meat Sci, 96(1), 47-55. https://doi.org/10.1016/j.meatsci.2013.06.004

Akgün, B., Genç, S., Arıc1, M. (2018). Tuz: g1dalardaki alg1sı, fonksiyonlanı ve kullanımının azaltılmasına yönelik stratejiler. Akademik Grda, 16(3), 361-370. https://doi.org/10.24323/ akademik-gida. 475397
Alim, A., Song, H., Liu, Y., Zou, T., Zhang, Y., Zhang, S. (2018). Flavour-active compounds in thermally treated yeast extracts. J Sci Food Agr, 98(10), 3774-3783. https://doi.org/ 10.1002/jsfa.8891

Bayrak, D., Anlar, P., Feyza, Z., Oral, Y., Kaya, M., Kaban, G. (2021). Furosine and $N \varepsilon$ carboxymethyl-lysine in cooked meat product (kavurma): Effects of salt and fat levels during storage. J Stored Products Research, 93 (July), 101856. https://doi.org/10.1016/j.jspr.2021.101 856

Bayraktar, F. (2017). Isıl işlem görmüş sucuk üretiminde potasyum klorür kullanımının ürün özelliklerine etkileri. Atatürk Üniversitesi, Fen Bilimleri Enstitüsü, Yüksek Lisans Tezi, Erzurum.

Bidlas, E., Lambert, R. J. W. (2008). Comparing the antimicrobial effectiveness of $\mathrm{NaCl}$ and $\mathrm{KCl}$ with a view to salt/sodium replacement. Int J Food Microbiol, 124(1), 98-102. https://doi.org/ 10.1016/j.ijfoodmicro.2008.02.031

Bingöl E.B., Bostan K. (2012). Bir g1da katk1 maddesi olarak laktatların et ve et ürünlerinde kullanım1. İstanbul Üniversitesi Veteriner Fakültesi Dergisi, 38(1), 79-88-88. https://doi.org/ 10.16988/iuvfd.86496

Bistola, V., Arfaras-Melainis, A., Trogkanis, E., Bakosis, G., Polyzogopoulou, E., Karavidas, I. N., Karavidas, A. (2020). Safety and efficacy of salt substitution with a low sodium-potassium enriched dietary salt in patients with heart failure with reduced ejection fraction: A pilot study. Clinical Nutrition ESPEN, 35, 90-94. https://doi.org/10.1016/j.clnesp.2019.11.004

Campo, R., Rosato, P., Giagnacovo, D. (2020). Less salt, same taste: food marketing strategies via healthier products. Sustainability, 12(9), 3916. https://doi.org/10.3390/su12093916

Cappuccio, F. P.,Beer, M., Strazzullo, P. (2019). Population dietary salt reduction and the risk of cardiovascular disease. A scientific statement from the European Salt Action Network. Nutrition, Metabolism and Cardiovascular Diseases, 29(2), 107-114. https://doi.org/10.1016/ j.numecd.2018.11.010 
Cepanec, K., Vugrinec, S., Cvetković, T., Ranilović, J. (2017). Potassium Chloride-Based Salt Substitutes: A Critical Review with a Focus on the Patent Literature. Comprehensive Reviews in Food Sci Food Safety, 16(5), 881-894. https://doi.org/10.1111/1541-4337.12291

Chapman, S. ve Speirs, C. (2014). Campden BRI Station Road Chipping Campden Review of Current Salt Replacing Ingredients. https://www.campdenbri.co.uk/news/june12c.p hp (Erişim:10.05.2020)

Chestnov, O., Mendis, S., Bettcher, D. (2013). A milestone in the response to non-communicable diseases. The Lancet, 382(9891), 481-482. https://doi.org/10.1016/S0140-6736(13)614579

Choi, Y. M., Jung, K. C., Jo, H. M., Nam, K. W., Choe, J. H., Rhee, M. S., Kim, B. C. (2014). Combined effects of potassium lactate and calcium ascorbate as sodium chloride substitutes on the physicochemical and sensory characteristics of low-sodium frankfurter sausage. Meat Sci, 96(1), 21-25. https://doi.org/10.1016/ j.meatsci.2013.06.022

Conroy, P. M., O’Sullivan, M. G., Hamill, R. M., Kerry, J. P. (2019). Sensory optimisation of saltreduced corned beef for different consumer segments. Meat Sci, 154 (February 2018), 1-10. https://doi.org/10.1016/j.meatsci.2019.03.015

CTAC (2009).Reformulation of products to reduce sodium: Salt Reduction guide for the Food Industry. https://www.foodtechcanada.ca/ wp-content/uploads/2018/05/Salt-reductionguide-for-the-food-industry.pdf Tarihi:03.05.2020)

Desmond, E. (2006). Reducing salt: A challenge for the meat industry. Meat Sci. https://doi.org/10.1016/j.meatsci.2006.04.014

Desmond, E., Vasilopoulos, C. (2019). Reducing salt in meat and poultry products. In Reducing Salt in Foods (Second Edi). https://doi.org/ 10.1016/b978-0-08-100890-4.00007-x

Dötsch, M., Busch, J., Batenburg, M., Liem, G., Tareilus, E., Mueller, R., Meijer, G. (2009). Strategies to reduce sodium consumption: A food industry perspective. Critical Reviews in Food Sci Nutr, 49(10), 841-851. https://doi.org/10.1080/ 10408390903044297

Ekmekçi, M. (2012). Tuzu Azaltılmış Pastırma Üretiminde Potasyum Klorür ve Kalsiyum Klorür Kullanımının Bazı Kalite Özellikleri Üzerine Etkileri. Ankara Üniversitesi, Fen Bilimleri Enstitüsü, Yüksek Lisans Tezi, Ankara, 77.

Engeloug, A. M., Yi, G., Egelandsdal, B., Haug, A., Nordvi, B. (2017). Commercial mineral enhanced dairy by-products as sodium replacers, antioxidants and calcium fortifiers in sausages. $J$ Food Sci, 82(6), 1302-1309. https://doi.org/ 10.1111/1750-3841.13718

Erkoyun, E., Sözmen, K., Bennett, K., Unal, B., Boshuizen, H. C. (2016). Predicting the health impact of lowering salt consumption in Turkey using the DYNAMO health impact assessment tool. Public Health, 140, 228-234. https://doi.org/10.1016/j.puhe.2016.04.014

European Commission (2020). https://ec.europa.eu/jrc/en/health-knowledgegateway/promotion-prevention/nutrition/salt (Erişim:07.06.2020)

Flores, M. (2018). Understanding the implications of current health trends on the aroma of wet and dry cured meat products. Meat Sci, 144, 53-61. https://doi.org/10.1016/j.meatsci.2018.04.016

Gaudette, N. J., Pietrasik, Z., Johnston, S. P. (2019). Application of taste contrast to enhance the saltiness of reduced sodium beef patties. $L w t$ Food Sci Techn, 116(June), 108585. https://doi.org/10.1016/j.lwt.2019.108585

Ge, G., Han, Y., Zheng, J., Zhao, M., Sun, W. (2020). Physicochemical characteristics and gelforming properties of myofibrillar protein in an oxidative system affected by partial substitution of $\mathrm{NaCl}$ with $\mathrm{KCl}, \mathrm{MgCl} 2$ or $\mathrm{CaCl} 2$. Food Chem, 309 (October 2019), 1-7. https://doi.org/ 10.1016/j.foodchem.2019.125614

Gelabert, J., Gou, P., Guerrero, L., Arnau, J. (2003). Effect of sodium chloride replacement on some characteristics of fermented sausages. Meat Sci, 65(2), 833-839. https://doi.org/10.1016/ S0309-1740(02)00288-7 
Gore, E., Mardon, J., Cécile, B., Lebecque, A. (2019). Calcium lactate as an attractive compound to partly replace salt in blue-veined cheese. J Dairy Sci, 102(1), 1-13. https://doi.org/10.3168/ jds.2018-15008

Gökalp, H.Y., Kaya, M., Zorba, Ö. (2012). Et Ürünleri İşleme Mühendisliği. Atatürk Üniversitesi, Yayın No: 786, Ziraat Fakültesi Yayın No: 320, Ders Kitapları Serisi: 70, Atatürk Üniversitesi. Ziraat Fakültesi. Ofset Tesisi, Erzurum

Greiff, K., Staurem, C. J., Nordvi, B., Rustad, T. (2015). Novel utilization of milk-based ingredients in salt reduced fish pudding. $L W T$ Food Sci Techn, 63(1), 92-99. https://doi.org/ 10.1016/j.lwt.2015.03.073

Gullon, P., Astray, G., Gullón, B., Franco, D., Campagnol, P. C. B., Lorenzo, J. M. (2020). Inclusion of seaweeds as healthy approach to formulate new low-salt meat products. Current Opinion in Food Science. https://doi.org/10.1016/ j.cofs.2020.05.005

Guo, X., Tao, S., Pan, J., Lin, X., Ji, C., Liang, H.,Li, S. (2020). Effects of L-Lysine on the physiochemical properties and sensory characteristics of salt-reduced reconstructed ham. Meat Sci, 166 (April). https://doi.org/10.1016/ j.meatsci.2020.108133

He, F. J., Macgregor, G. A. (2012). Salt intake, plasma sodium, and worldwide salt reduction. Annals of Medicine, 44(SUPPL. 1). https:/ / doi.org/ 10.3109/07853890.2012.660495

Henney, J. E., Taylor, C. L., Boon, C. S. (2010). Strategies to reduce sodium intake in the United States. In Strategies to Reduce Sodium Intake in the United States. https://doi.org/10.17226/12818

Henry-Unaeze, H. N. (2017). Update on food safety of monosodium L-glutamate (MSG). Pathophysiology, 24(4), 243-249. https://doi.org/ 10.1016/j.pathophys.2017.08.001

Hoppu, U., Hopia, A., Pohjanheimo, T., RotolaPukkila, M., Mäkinen, S., Pihlanto, A., Sandell, M. (2017). Effect of Salt Reduction on Consumer Acceptance and Sensory Quality of Food. Foods,
6(12), $\quad$ 103. https://doi.org/10.3390/ foods6120103

Inguglia, E. S.,Zhang, Z., Tiwari, B. K., Kerry, J. P., Burgess, C. M. (2017). Salt reduction strategies in processed meat products - A review. Trends in Food Sci Techn, 59, 70-78. https://doi.org/ 10.1016/j.tifs.2016.10.016

Kabil E., Hazar F. Y., Kaban G., Kaya M. (2020). Farklı Tuz Oranları Kullanılarak Üretilen Pastırma Çeşitlerinin Yağ Asidi Kompozisyonu, IV. Et Ürünleri Çalıştayı, Aydın, Türkiye, 6 - 08 Ekim 2020, ss.84

Kameník, J., Saláková, A., Vyskočilová, V., Pechová, A., Haruštiaková, D. (2017). Salt, sodium chloride or sodium? Content and relationship with chemical, instrumental and sensory attributes in cooked meat products. Meat Sci, 131(May), 196-202. https://doi.org/ 10.1016/j.meatsci.2017.05.010

Kaur, R., Sharma, M. (2019). Cereal polysaccharides as sources of functional ingredient for reformulation of meat products: A review. J Funcl Foods, 62 (August), 103527. https://doi.org/10.1016/j.jff.2019.103527

Kilcast, D., Ridder, C. (2007). Sensory issues in reducing salt in food products. In Reducing Salt in Foods: Practical Strategies. https://doi.org/10.1533/ 9781845693046.2.201

Kim, Y. H., Keeton, J. T., Smith, S. B., Maxim, J. E., Yang, H. S., Savell, J. W. (2019). Evaluation of antioxidant capacity and colour stability of calcium lactate enhancement on fresh beef under highly oxidising conditions. Food Chem, 115(1), 272-278. https://doi.org/10.1016/ j.foodchem.2008.12.008

Kloss, L., Meyer, J. D., Graeve, L., Vetter, W. (2015). Sodium intake and its reduction by food reformulation in the European Union - A review. NFS Journal, 1, 9-19. https://doi.org/ 10.1016/j.nfs.2015.03.001

Li, S., Li, L., Zhu, X., Ning, C., Cai, K., Zhou, C. (2019). Conformational and charge changes induced by L-Arginine and L-lysine increase the solubility of chicken myosin. Food Hydrocolloids, 
89(2018), $330-336$. https://doi.org/10.1016/j.foodhyd.2018.10.059

Luta, X., Hayoz, S., Krause, C. G., Sommerhalder, K., Roos, E., Strazzullo, P. (2018). Nutrition , Metabolism and Cardiovascular Diseases The relationship of health / food literacy and salt awareness to daily sodium and potassium intake among a workplace population in Switzerland. Nutrition, Metabolism and Cardiovascular Diseases, 28(3), 270-277. https://doi.org/10.1016/ j.numecd.2017.10.028

Mariutti, L. R. B.,Bragagnolo, N. (2017). Influence of salt on lipidoxidation in meat and sea food products: A review. Food Res Int, 94, 90-100. https://doi.org/10.1016/j.foodres.2017.02.003

Mitchell, H. L. (2019). In Reducing Salt in Foods (Second Edition). Alternative ingredients to sodium chloride https://doi.org/10.1016/B9780-08-100890-4.00005-6

Mora-Gallego, H., Guàrdia, M. D., Serra, X., Gou, P., Arnau, J. (2016). Sensory characterisation and consumer acceptability of potassium chloride and sunflower oil addition in small-caliber non-acid fermented sausages with a reduced content of sodium chloride and fat. Meat Science, 112, 9-15. https://doi.org/10.1016/j.meatsci.2015.10.008

Omana, D. A., Plastow, G., Betti, M. (2011). The use of $b$-glucan as a partial salt replacer in high pressure processed chicken breast meat. Food Chemistry, 129(3), 768-776. https://doi.org/ 10.1016/j.foodchem.2011.05.018

Parniakov, O., Mikhrovska, M., Toepfl, S., Roselló-Soto, E., Pinto, C. A., Saraiva, J. A., Barba, F. J. (2020). Current and future strategies to reduce salt consumption. In Agri-Food Industry Strategies for Healthy Diets and Sustainability. https://doi.org/10.1016/b978-0-12-817226-

1.00006-0

Pandian, J. D., Gall, S. L., Kate, M. P., Silva, G. S., Akinyemi, R. O., Ovbiagele, B. I.,Thrift, A. G. (2018). Prevention of stroke: a global perspective. The Lancet, 392(10154), 1269-1278. https://doi.org/10.1016/S0140-6736(18)312698
Pandya, J. K., Decker, K. E., Goulette, T., Kinchla, A. J. (2020). Sodium reduction in Turkey breast meat by using sodium anion species. $L w t$ Food Sci Techn, 124(2019), 109110. https://doi.org/10.1016/j.lwt.2020.109110

Petit, G., Jury, V., Lamballerie, M., Duranton, F., Pottier, L., Martin, J. L. (2019). Salt Intake from Processed Meat Products: Benefits, Risks and Evolving Practices. Comprehensive Reviews in Food Sci Food Safety, 18(5), 1453-1473. https://doi.org/10.1111/1541-4337.12478

Pinna, A.,Saccani, G., Schivazappa, C., Simoncini, N., Virgili, R. (2020). Revision of the cold processing phases to obtain a targeted salt reduction in typical Italian dry-cured ham. Meat Sci, 161, 107994. https://doi.org/10.1016/ j.meatsci.2019.107994

Powles, J., Fahimi, S., Micha, R., Khatibzadeh, S., Shi, P., Ezzati, M., Mozaffarian, D. (2013). Global, regional and national sodium intakes in 1990 and 2010: A systematic analysis of $24 \mathrm{~h}$ urinary sodium excretion and dietary surveys worldwide. BMJ Open, 3(12). https://doi.org/10.1136/bmjopen-2013-003733

Pretorius, B., Schönfeldt, H. C. (2018). The contribution of processed pork meat products to total salt intake in the diet. Food Chem, 238, 139145. j.foodchem.2016.11.078

https://doi.org/10.1016/

Raybaudi-Massilia, R., Mosqueda-Melgar, J., Rosales-Oballos, Y., Citti de Petricone, R., Frágenas, N. N., Zambrano-Durán, A.,Urbina, G. (2019). New alternative to reduce sodium chloride in meat products: Sensory and microbiological evaluation. Lwt- Food Sci Techn, 108(2018), 253260. https://doi.org/10.1016/j.lwt.2019.03.057

Resende, J., Silva, G., Paula, A., Pires, D. S., Oliveira, D. C. De, Riani, V., Condoncelli, L. (2020). Acta Scientiarum Technological and sensory analysis of beef burger replacing $\mathrm{NaCl}$ with $\mathrm{KCl}$ and flavor enhancer. 1-8. https://doi.org/10.4025/ actascitechnol.v42i1.45632

Ruusunen, M., Niemistö, M., Puolanne, E. (2002). Sodium reduction in cooked meat products by using commercial potassium phosphate mixtures. 
Agr Food Sci in Finland, 11(3), 199-207. https://doi.org/10.23986/afsci.5725

Ruusunen, M., Vainionpa, J., Niemisto, M. (2003). Effect of sodium citrate, carboxymethyl cellulose and carrageenan levels on quality characteristics of low-salt and low-fat bologna type sausages. 64, 371-381. https://doi.org/10.1016/S0309-1740(02)00178$\mathrm{X}$

Omana, D. A., Plastow, G., Betti, M. (2011). The use of $\beta$-glucan as a partial salt replacer in high pressure processed chicken breast meat. Food Chem, 129(3), 768-776. https://doi.org/10.1016/ j.foodchem.2011.05.018

Öztürk, İ., Garipağaoğlu, M. (2018). Salt Consumption and Health: Review. Turkiye Klinikleri Journal of Health Sciences, 3(1), 57-65. https://doi.org/10.5336/healthsci.2017-55160

Sağllk Bakanlığı, 2016. Türkiye Halk Sağlı̆̆1 Kurumu Obezite, Diyabet ve Metabolik Hastalıklar Daire Başkanlığı. [The world's taking action to reduce excessive salt/sodium intake]. Türkiye Aşırı Tuz Tüketiminin Azaltılması Program1 2017-2021. 2. Bask1. Ankara: Sağlık Bakanlı̆̆1 Yayınlarl; p.61.

Sağlık Bakanlığı, 2019. Gıda ve içecek sektörü için protokol uygulama ve tuz azaltma rehberi https://www.tgdf.org.tr/wpcontent/uploads/2020/02/Tuz-AzaltmaRehberi.pdf (Erişim:16.06.2020)

Stanley, R. E., Bower, C. G., Sullivan, G. A. (2017). Influence of sodium chloride reduction and replacement with potassium chloride based salts on the sensory and physico-chemical characteristics of pork sausage patties. Meat $S_{c i}$, 133(5), 36-42. https://doi.org/10.1016/ j.meatsci.2017.05.021

Şimsek, D. (2016). Sucuk üretiminde farklı klorür tuzlarının kullanım imkanları. Atatürk Üniversitesi, Fen Bilimleri Enstitüsü, Yüksek Lisans Tezi

Taladrid, D., Laguna, L., Bartolomé, B., MorenoArribas, M. V. (2020). Plant-derived seasonings as sodium salt replacers in food. Trends in Food Sci Techn 99(2019), 194-202. https://doi.org/10.1016/j.tifs.2020.03.002
Tamm, A., Bolumar, T., Bajovic, B., Toepfl, S. (2016). Salt $(\mathrm{NaCl})$ reduction in cooked ham by a combined approach of high pressure treatment and the salt replacer $\mathrm{KCl}$. Innovative Food Sci Emerging Techn, 36, 294-302. https://doi.org/10.1016/j.ifset.2016.07.010

Tarte, R. (Ed.). (2009). Ingredients in Meat Products. Joseph G. S. Basic Curing Ingredients, 6-7. https://doi.org/10.1007/978-0-387-71327-4

Taylor, C., Doyle, M., Webb, D. (2018). "The safety of sodium reduction in the food supply: A cross-discipline balancing act" Workshop proceedings. Critical Reviews in Food Sci Nutr, 58(10),1650-1659.

https://doi.org/10.1080/10408398.2016.127643 1

Thomas-Danguin, T., Guichard, E., Salles, C. (2019). Cross-modal interactions as a strategy to enhance salty taste and to maintain liking of lowsalt food: A review. Food and Function, 10(9), 52695281. https://doi.org/10.1039/c8fo02006j

Trieu, K.,McMahon, E., Santos, J. A., Webster, J. (2017). Review of behaviour change interventions to reduce population salt intake. J Nutr Intermediary Metabolism, 8, 118. https://doi.org/10.1016/ j.jnim.2017.04.218

Triki, M., Khemakhem, I., Trigui, I., Salah, R. Ben, Jaballi, S., Ruiz-capillas, C.,Besbes, S. (2017). Free-sodium salts mixture and AlgySalt ${ }^{\circledR}$ use as $\mathrm{NaCl}$ substitutes in fresh and cooked meat products intended for the hypertensive population. Meat Sci, 133(July), 194-203. https://doi.org/10.1016/j.meatsci.2017.07.005

USDA (2018). Nutrient Data Laboratory Home Page. United States Department of Agriculture. https://fdc.nal.usda.gov/ (Erişim Tarihi: 10.06.2020).

Vidal, V. A. S., Bernardinelli, O. D., Paglarini, C. S., Sabadini, E., Pollonio, M. A. R. (2019). Understanding the effect of different chloride salts on the water behavior in the salted meat matrix along 180 days of shelf life. Food Res Int, 125(8), 108634. https://doi.org/10.1016/ j.foodres.2019.108634 
Vidal, V. A. S.,Paglarini, C. S., Freitas, M. Q., Coimbra, L. O., Esmerino, E. A., Pollonio, M. A. R., Cruz, A. G. (2020). Q Methodology: An interesting strategy for concept profile and sensory description of low sodium salted meat. Meat Sci, https://doi.org/10.1016/j.meatsci.2019.108000

Weiss, J., Gibis, M., Schuh, V., Salminen, H. (2010). Advances in ingredient and processing systems for meat and meat products. Meat Sci, 86(1), 196-213. https://doi.org/10.1016/ j.meatsci.2010.05.008

Wen, R., Hu, Y., Zhang, L., Wang, Y., Chen, Q., Kong, B. (2019). Effect of $\mathrm{NaCl}$ substitutes on lipid and protein oxidation and flavor development of Harbin dry sausage. Meat Sci, 156(February), 33-43. https://doi.org/10.1016/ j.meatsci.2019.05.011

World Health Organization WHO. (2012). Guideline: Sodium intake for adults and children., Geneva,Switzerland $1-56$. https://www.who.int/publications/i/item/9789 241504836 (Erişim Tarihi:04.05.2020)

World Health Organization WHO. (2020). Salt reduction https://www.who.int/newsroom/fact-sheets/detail/salt-reduction (Erişim Tarihi:31.05.2020)

Yilmaz Oral Z. F. , Kaban G. (2021). Salt (NaCl) reduction in sucuk, heat-treated sucuk and pastırma. International Symposium of Scientific Research and Innovative Studies, Balıkesir, Türkiye, 22 Şubat - 25 Nisan 2021, ss.1-9

Zheng, J., Han, Y., Ge, G., Zhao, M., Sun, W. (2019). Partial substitution of $\mathrm{NaCl}$ with chloride salt mixtures: Impact on oxidative characteristics of meat myofibrillar protein and their rheological properties. Food Hydrocolloids, 96 (December 2018), 36-42. https://doi.org/10.1016/ j.foodhyd.2019.05.003 